\title{
EXPANDING THE BOUNDARY OF BRAND EXTENSIONS THROUGH BRAND RELATIONSHIP QUALITY
}

\author{
Esra ARIKAN ${ }^{1}$, Cengiz YILMAZ ${ }^{2}$, Muzaffer BODUR ${ }^{3}$ \\ ${ }^{1}$ Istanbul Bilgi University, Istanbul, Turkey \\ ${ }^{2}$ Middle East Technical University, Ankara, Turkey \\ Abdullah Gul University, Kayseri, Turkey \\ ${ }^{3}$ Bogazici University, Istanbul, Turkey \\ E-mail: ${ }^{1}$ esra.arikan@bilgi.edu.tr (corresponding author)
}

Received 8 June 2015; accepted 1 August 2016

\begin{abstract}
Research on brand extensions identifies the concept of perceived fit as the prime determinant of success. Yet, it is not difficult to find examples of brands that have been extended successfully into "perceptually distant" domains. In an attempt to resolve this discrepancy between research insights and practical experiences, the study investigates the role of Brand Relationship Quality (BRQ) as a critical factor determining consumer responses to brand extensions. The proposed model is tested separately in the context of three different fit scenarios (high, moderate, and low) with data from 502 consumers. The results indicate that BRQ and perceived fit exert independent effects on consumer responses and complement each other as they jointly influence evaluations of brand extensions. The study therefore extends existing theory by providing evidence that the brand extension phenomenon cannot be explained justly without including constructs that portray personal relationships consumers develop with brands and provides insights for marketers and researchers as to how such relationships can be integrated in formulations of successful brand extension strategies.
\end{abstract}

Keywords: brand extension, brand relationship quality, perceived fit, consumer behaviour, consumer responses, brand management.

JEL Classification: M31.

\section{Introduction}

The current state of research on brand extensions identifies the concept of perceived fit as the prime determinant of success. This line of research asserts that marketers should launch brand extensions characterized by high levels of perceived fit and avoid introducing extensions marked by low levels of fit (Aaker, Keller 1990). Yet, it is not difficult to find examples of brands that have been extended successfully into "perceptually distant" domains (Klink, Smith 2001). It is also well known that several brand extensions expected to be "sure triumphs" due to favorable fit perceptions have failed dramatically. 
One possible explanation for this divergence between research findings and marketplace observations is that so far only direct relationships between success factors and brand extension outcomes have been studied and nomologically more complicated relational structures have been disregarded (Völckner, Sattler 2006). Another explanation highlights the importance of a number of critical factors largely ignored in prior research (Chun et al. 2015). Both accounts suggest that failure in prior research to take such issues into account may have resulted in overstatements of the role of perceived fit in brand extension research. It is therefore necessary to investigate the role of perceived fit together with other factors for a better understanding of their joint and relative effects. One such important subject that needs to be integrated into explanations of the brand extension phenomenon is the notion that brands may become special relationship entities for individual consumers.

This study aims to expand the scope of brand extension research by focusing on the personal relationships consumers develop with brands. Consistent with the long-held foundations of relationship marketing theory (e.g., Morgan, Hunt 1994), the central thesis of the study is that personal relationships consumers develop with brands play a focal role, together with fit perceptions, in determining brand extension success. Accordingly, in an attempt to resolve the aforementioned discrepancies between research insights and practical experiences, the study advances the construct of Brand Relationship Quality (hereafter, BRQ) as a key factor influencing consumer responses to brand extensions.

Originally developed by Fournier (1994), BRQ refers to the strength and depth of a consumer-brand relationship. By positing BRQ as a focal determinant of consumer reactions to brand extensions together with fit perceptions and by investigating the relative effects of each, the study aims to highlight the personal nature of consumer-brand relationships and reveal a more accurate understanding of the role of fit perceptions in brand extensions. Realizing that the relationships of interest may vary across differing levels of fit perceptions, the study explores the relationships of concern separately in three different extension contexts of high-fit, moderate-fit, and low-fit.

\section{Theoretical framework and research model}

\subsection{Perceived fit}

The construct of perceived fit has indisputably generated utmost interest in brand extensions research. Drawing primarily on categorization theory (e.g., Mervis, Rosch 1981), the degree to which brand associations transfer to an extension depends heavily on the level of perceived fit between the parent brand and the extension. While a good fit enhances affect transfer from the brand to the extension, a poor fit may deter the transfer of positive associations and even stimulate undesirable beliefs (Aaker, Keller 1990). Thus, unless there is a recognizable basis for fit, consumers usually disapprove of extensions (Lane 2000). The importance of perceived fit as a success factor is well established in the related literature (Albrecht et al. 2013; Hem et al. 2014; Goedertier et al. 2015; Dens, De Pelsmacker 2016). 
H1: Level of perceived fit between the parent brand and the extension is positively associated with consumers' (a) favorable attitudinal responses and (b) favorable behavioral responses toward brand extensions.

\subsection{Brand relationship quality}

A prevailing stream of research in brand management highlights the importance of personal relationships consumers may have with brands. This view depicts a consumer and a brand in a dyadic relationship similar to relationships between individuals (Fournier 1994). A few prominent attempts in the brand extensions context emphasize the importance of the BRQ construct. Park and Kim (2001) hypothesize that consumers having a strong relationship with a brand might react to its extensions more positively than those lacking such a relationship. In another study, Park et al. (2002) further reveal that strong BRQ subjects evaluate extensions more positively than weak BRQ subjects do. Works focusing on brand affect (Yeung, Wyer 2005; Fedorikhin et al. 2008) also suggest that consumers may evaluate brand extensions on the basis of subjective affective reactions to the parent brand, without considering specific features of the extension itself, particularly at earlier phases of the extension's marketplace existence. More important, a recent work by Kim et al. (2014) demonstrates that BRQ effects on consumer judgments generalize across cultural contexts. Consistently, the present study posits that consumers with highly favorable assessments of their personal relationships with a brand will have more positive evaluations of its extension products than low BRQ consumers.

H2: BRQ is positively associated with consumers' (a) favorable attitudinal responses and (b) favorable behavioral responses toward brand extensions.

This study further suggests a positive effect of BRQ on fit perceptions. This hypothesized relationship is critical because it stresses the focal role of BRQ in determining brand extension success. The expectation that a favorable BRQ positively influences fit perceptions is based on the view that brand-elicited affect may facilitate perceptions that the extension belongs to the parent brand's category, particularly in cases where the relationship between the parent category and the extension is ambiguous (Yeung, Wyer 2005). As Fedorikhin et al. (2008) assert, consumers with strong emotional bonds with the parent brand usually have a pervasive desire to maintain their scope of interactions with brand-related phenomena, which motivates them to view and categorize the extension as part of the parent brand's schema.

H3: BRQ is positively associated with the perceived fit between the parent brand and the extension.

\subsection{Antecedent brand characteristics}

Based on an extensive literature search, two major parent brand characteristics, namely, brand quality and brand portfolio breadth have been identified as affecting consumer responses to brand extensions. In addition to their direct effects, each antecedent factor is hypothesized to enhance BRQ assessments and fit perceptions and thereby exert indirect effects on consumer responses. 
Brand quality. Consistent with the transfer of associations paradigm, consumers generally use the parent brand as a basis to infer attributes about the extension product (Wernerfelt 1988). Because consumers have not actually tried the extension product to be able to judge its quality, they rely on the known brand name to draw inferences about quality. A higher quality parent brand implies more positive evaluations of the extension, since the market considers the quality of the parent brand as a guarantee for the quality of the new product. Indeed, a number of studies demonstrate positive and significant relationships between perceived brand quality and success likelihood of its extensions (Völckner, Sattler 2006; Dens, De Pelsmacker 2010; Hem et al. 2014).

H4: The quality of the parent brand is positively associated with consumers' (a) favorable attitudinal responses and (b) favorable behavioral responses toward brand extensions.

In a similar vein, a high quality image also implies competence and superiority in skills to operate in different categories, which might reflect directly upon assessments of fit. Indeed, examining online brand extensions, Song et al. (2010) find a significant positive association between perceived quality of parent brands and perceived fit. The role of parent brand quality in terms of determining BRQ assessments is even more obvious. Fournier (1994) asserts that strong brand relationships are rooted in superior product performance. In other words, consumers are more likely to develop positive affect toward brands of superior quality (Grisaffe, Nguyen 2011). Supporting this view, Batra et al. (2012) investigate the nature of brand love and find that perceptions of high quality predict brand love strongly.

H5: The quality of the parent brand is positively associated with (a) the perceived fit between the parent brand and the extension and (b) BRQ.

Brand portfolio breadth. Brand portfolio breadth refers to both the number of product categories as well as the degree of (dis)similarity between the product categories under the brand's name (Boush, Loken 1991). Prior research suggests that systematic extensions of a brand can actually strengthen its position in the minds of consumers. As Wernerfelt (1988) states, recognizing the magnitude of the firm's investments and reflecting this as a signal of quality, consumers are more favorably inclined toward brands with greater number of products. Similarly, Dacin and Smith (1994) find a positive relationship between the number of products affiliated with a brand and consumers' confidence in and favorability of their evaluations of extensions. Other studies further indicate positive relationships between portfolio breadth and evaluations of extensions (DelVecchio 2000; Meyvis, Janiszewski 2004; John, Park 2016).

H6: The breadth of the brand portfolio is positively associated with consumers' (a) favorable attitudinal responses and (b) favorable behavioral responses toward brand extensions.

Additionally, brand portfolio breadth can influence perceptions of fit for a brand extension. A brand with a limited portfolio would have well but narrowly defined schemata and even a moderately incongruous new product would be perceived as not fitting, while extensions from a broad portfolio would be deemed fitting (Sheinin, Schmitt 1994). In 
effect, several scholars posit that the main path through which brand portfolio breath relates to consumer evaluations of extensions is through fit perceptions rather than being direct in nature (Grime et al. 2002; Völckner, Sattler 2007).

Regarding the effects of brand portfolio breadth on BRQ, the concept of norms of reciprocity in social exchange theory (Emerson 1976) as well as the investment model suggests that as partners invest more time, effort, and money in a relationship, or as shared memories expand, the relationship eventually evolves towards a high-commitment type relationship. De Wulf et al. (2001) find that perceptions of relationship investments on the part of the other party foster perceived relationship quality and behavioral loyalty. Palmatier et al. (2006) also report a positive effect between mutual investments and perceived relationship quality. Consumers have a tendency to develop stronger relationships with "broader" brands because there are greater chances for frequent contacts and a broad portfolio indicates commitment on the part of the parent brand.

H7: The breadth of the brand portfolio is positively associated with (a) the perceived fit between the parent brand and the extension and (b) BRQ.

Finally, concerning the relationship between attitudinal and behavioural responses of consumers, researchers usually incorporate theoretical support from the theory of reasoned action. According to this theory, behaviour is a function of an attitude reflecting a combination of evaluative judgments and feelings toward performing a particular

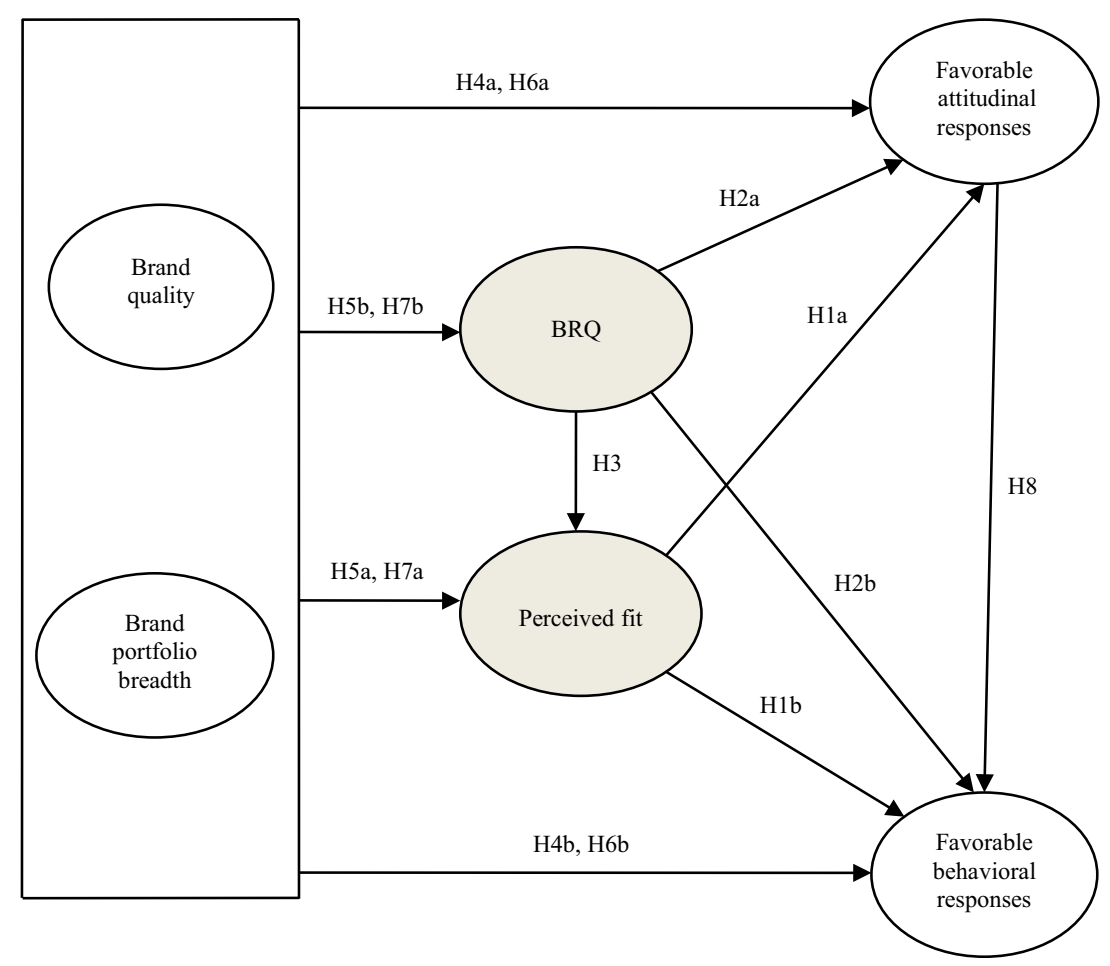

Fig. 1. Proposed model 
behaviour (Fishbein, Ajzen 1975). Most studies in the brand extension literature have not differentiated between attitudinal and behavioural responses. However, this study distinguishes between attitudinal and behavioral responses based on the expectation that the relative effects of perceived fit and BRQ on each response type will vary. Whereas no formal hypotheses are posited regarding the nature of such differences in effects, it is hypothesized following the conventional view that attitudes shall precede behaviors.

H8: Favorable attitudinal responses toward brand extensions are positively associated with favorable behavioral responses.

The proposed model is depicted in Figure 1. BRQ and perceived fit are posited as exerting direct effects on attitudinal and behavioral responses to brand extensions, while at the same time mediating the effects of parent brand quality and brand portfolio breadth. The focal role attributed to BRQ is stressed further based on its hypothesized direct effect on fit perceptions.

\section{Methodology}

\subsection{Selection of stimuli}

A semi-structured focus group with doctoral students at a university in Turkey provided insights regarding the product category, brands, and hypothetical extension products suitable for the study purposes. The major home appliances category (refrigerators, televisions, etc.) was selected to serve as the parent brand category. Three actual brands currently existing in the Turkish market, each with strong existence in this product category and each well-known to the respondents, were then selected as parent brands to be studied. These brands have already been extended to different categories, enabling the measurement of brand portfolio breadth. Next, three extension product categories equally applicable to all three brands were selected by the participants. These products were automobile cooler fridges (high-fit), digital blood pressure monitor (moderate-fit), and wristwatches (low-fit).

\subsection{Measures and data collection}

All measures employed multi-item scales and all were adopted from prior works and adapted to the current context. Items were 6-point Likert scales or semantic differential scales. Following prior research, BRQ was operationalized as a higher-order construct and the original items by Fournier (1994) were used to measure each dimension. In order to measure parent brand quality, a five-item scale based on the studies of Dodds et al. (1991) and Keller and Aaker (1992) was adopted. A five-item scale that originates from Boush and Loken (1991) and Dacin and Smith (1994) was used to measure brand portfolio breadth. For perceived fit, the four-item measure by Fedorikhin et al. (2008) was used, along with three additional items frequently used in the brand extension literature. For attitudinal responses, following Hem et al. (2014), three items that measure overall attitudes toward brand extensions were used. For behavioral responses, five items capturing purchasing intensions, word-of-mouth (WOM) intentions, and willingness to search for the extension were adopted from Fedorikhin et al. (2008) and Völckner, Sattler (2007). 
The questionnaire was administered face-to-face by professional interviewers to a randomly selected sample of consumers in the city of Istanbul. Specifically, a sampling frame listing all the districts in the city was first compiled and then a two-stage area sampling process was employed to select fifty random districts and subsequently fifteen random households from each district. Of the 750 individuals contacted, 502 completed the questionnaire, yielding a response rate of 66.9 percent. As each respondent provided information for one brand and its three hypothetical extensions, evaluations for 1506 brand extension cases were collected. Table 1 provides a summary of the demographic profiles of the respondents.

Table 1. Respondent profile

\begin{tabular}{lc}
\hline \multicolumn{2}{c}{ Gender } \\
\hline \multicolumn{2}{c}{ Sample \% } \\
\hline Male & 49.4 \\
Female & 50.6 \\
\hline \multicolumn{2}{c}{ Age(in years) } \\
\hline 18-24 & 15.7 \\
25-34 & 33.3 \\
35-44 & 28.3 \\
45-54 & 14.1 \\
55 and over & 8.6 \\
\hline \multicolumn{2}{c}{ Level of education } \\
\hline Literate & 3.1 \\
Primary school & 37.1 \\
Secondary school & 15.7 \\
High school & 31.5 \\
University & 11.8 \\
Graduate school & 0.8 \\
\hline \multicolumn{2}{c}{ Current working status } \\
\hline Wage earner & 29.7 \\
Self-employed & 17.9 \\
Unemployed/job seeker & 4.8 \\
Housewife & 35.7 \\
Retired & 7.4 \\
Student & 4.5 \\
\hline
\end{tabular}

\section{Analyses}

\subsection{Measure assessments}

Data for the three brands were aggregated at this phase and measures were evaluated separately for each fit condition. Findings with regard to measurement model analyses across the three conditions were similar. Therefore, only the findings concerning the high fit condition are reported. Prior to the analyses of the overall measurement model via confirmatory factor analyses (CFA), exploratory factor analyses (EFA) were conducted to identify the factor structures of the observed variables. With the exception of 
BRQ, analyses revealed single-factor solutions for each construct. The BRQ measure was originally conceptualized to have seven distinct but interrelated dimensions; however, the results of the EFA produced a three-factor solution with 77 percent of the total variance explained. Thus, in the subsequent analyses, the seven conceptual dimensions of the BRQ construct were combined into the three broader dimensions which were labeled as "emotional connection", "partner quality and love", and "intimacy".

Next, the overall measurement model was subjected to a CFA, separately for each extension product. The fit statistics for the high-fit case were $\chi 2=502.413$, df $=213$, $\mathrm{p}<0.001 ; \mathrm{RMSEA}=0.052 ; \mathrm{TLI}=0.970 ; \mathrm{CFI}=0.975$ and $\mathrm{NFI}=0.958$, indicating a reasonable level of fit. The pattern of findings for the moderate and low- fit conditions were similarly supportive of the measurement model. As provided in Table 2, for all constructs composite reliability and average variance extracted estimates were above the recommended threshold levels, 0.6 and 0.5 respectively, indicating that measures were internally consistent. Similarly, the Cronbach's alpha estimates were all above the recommended threshold of 0.7 . To alleviate concerns about common method variance (CMV), Harman's single-factor test was used. All the items were subjected to an EFA to determine whether a single method factor explained a majority of variance. Multiple factors with Eigenvalues greater than 1 were reported, with the first factor accounting for $25 \%$ of the total variance explained $(78 \%)$, indicating there is no serious CMV problem.

Table 2. Measure assessments

\begin{tabular}{lccc}
\hline & $\begin{array}{c}\text { Average variance } \\
\text { extracted (AVE) }\end{array}$ & $\begin{array}{c}\text { Composite } \\
\text { reliability (CR) }\end{array}$ & $\begin{array}{c}\text { Cronbach's } \\
\text { Alpha }\end{array}$ \\
\hline Brand quality & 0.81 & 0.94 & 0.94 \\
\hline Brand portfolio breadth & 0.65 & 0.85 & 0.87 \\
\hline Perceived fit & 0.76 & 0.95 & 0.95 \\
\hline BRQ & 0.71 & 0.88 & 0.88 \\
\hline Attitudinal responses & 0.76 & 0.91 & 0.90 \\
\hline Behavioural responses & 0.83 & 0.95 & 0.95 \\
\hline
\end{tabular}

\subsection{Hypothesis testing}

The proposed model is tested separately for each extension condition. Fit indices for each condition suggest a good overall fit. These fit indices and estimated path coefficients are depicted in Table 3.

As predicted, the path from perceived fit to favorable attitudinal responses is positive and significant for all three extension products, supporting $\mathrm{H}_{1 \mathrm{a}}$. The path from perceived fit to favorable behavioral responses is also positive and significant in the moderate and low-fit conditions, partially supporting $\mathrm{H}_{1 \mathrm{~b}}$. Likewise, BRQ is found to have positive and significant effects on consumers' behavioral responses in all fit conditions, supporting $\mathrm{H}_{2 b}$. However, the path from BRQ to favorable attitudinal responses is nonsignificant in all fit conditions, failing to support $\mathrm{H}_{2 \mathrm{a}}$. The results further demonstrate a 
positive and significant path from BRQ to perceived fit for the high and moderate-fit conditions. For the low-fit condition, the effect of BRQ on perceived fit is nonsignificant. Thus, $\mathrm{H}_{3}$ is partially supported.

The results demonstrate a positive and significant direct effect from brand quality to favorable attitudinal responses only for the high-fit condition, partially supporting $\mathrm{H}_{4 \mathrm{a}}$. Yet, significant path coefficients from brand quality to favorable behavioral responses are observed for all fit conditions, supporting $\mathrm{H}_{4 \mathrm{~b}}$. Unexpectedly, the hypotheses suggesting a positive and significant relationship between brand portfolio breadth and consumers' responses to brand extensions are not supported. In the high-fit condition, there is a significant but negative path from brand portfolio breadth to favorable attitudinal responses. In the low-fit condition, the path coefficient from brand portfolio breadth to favorable behavioral responses is significant but again negative. In all other cases, parameter estimates for these two structural paths are non-significant. Thus, $\mathrm{H}_{6 \mathrm{a}}$ and $\mathrm{H}_{6 \mathrm{~b}}$ are not supported.

Table 3. Summary of the findings

\begin{tabular}{llccc}
\hline & \multicolumn{1}{c}{ Structural paths } & High fit & Moderate fit & Low fit \\
\hline H1a & Perceived fit $\rightarrow$ Attitudinal responses & $0.744^{* * *}$ & $0.686^{* * *}$ & $0.713^{* * *}$ \\
\hline H1b & Perceived fit $\rightarrow$ Behavioral responses & n.s & $0.241^{* * *}$ & $0.220^{* * *}$ \\
\hline H2a & BRQ $\rightarrow$ Attitudinal responses & n.s & n.s & n.s \\
H2b & BRQ $\rightarrow$ Behavioral responses & $0.217^{* * *}$ & $0.111^{*}$ & $0.068^{*}$ \\
\hline H3 & BRQ $\rightarrow$ Perceived fit & $0.161^{* *}$ & $0.641^{* * *}$ & n.s \\
\hline H4a & Brand quality $\rightarrow$ Attitudinal responses & $0.407^{* * *}$ & n.s & n.s \\
\hline H4b & Brand quality $\rightarrow$ Behavioral responses & $0.166^{*}$ & $0.134^{* *}$ & $0.104^{*}$ \\
\hline H5a & Brand quality $\rightarrow$ Perceived fit & n.s & n.s & n.s \\
\hline H5b & Brand quality $\rightarrow$ BRQ & $0.513^{* * *}$ & $0.516^{* * *}$ & $0.514^{* * *}$ \\
\hline H6a & Portfolio breadth $\rightarrow$ Attitudinal responses & $-0.169^{* *}$ & n.s & n.s \\
\hline H6b & Portfolio breadth $\rightarrow$ Behavioral responses & n.s & n.s & $-0.131^{* *}$ \\
\hline H7a & Portfolio breadth $\rightarrow$ Perceived fit & $0.606^{* * *}$ & n.s & n.s \\
\hline H7b & Portfolio breadth $\rightarrow$ BRQ & $0.201^{* *}$ & $0.197^{* *}$ & $0.201^{* *}$ \\
\hline H8 & Attitudinal Responses $\rightarrow$ Behavioral Responses & $0.695^{* * *}$ & $0.474^{* * *}$ & $0.726^{* * *}$ \\
\hline & $\chi 2$ (213) & 502.413 & 663.028 & 705.342 \\
\hline & p-value & 0.000 & 0.000 & 0.000 \\
\hline & RMSEA & 0.052 & 0.065 & 0.068 \\
\hline & TLI & 0.970 & 0.958 & 0.955 \\
\hline & NFI & 0.975 & 0.965 & 0.962 \\
\hline & & & 0.947 \\
\hline
\end{tabular}

Notes: ${ }^{* * *} \mathrm{p}<0.001,{ }^{* *} \mathrm{p}<0.01,{ }^{*} \mathrm{p}<0.05$. 
Regarding the effects of antecedent brand characteristics on perceived fit and BRQ, the results generally suggest stronger effects on BRQ in comparison to those on perceived fit. Regarding effects on fit perceptions, $\mathrm{H}_{5 \mathrm{a}}$ predicts a positive and direct effect of brand quality on perceived fit, but the results indicate non-significant effect sizes for all fit conditions, failing to support $\mathrm{H}_{5 \mathrm{a}}$. Furthermore, regarding the effects of portfolio breath on fit perceptions, the results indicate a positive and significant relationship for the highfit condition only, thus partially supporting $\mathrm{H}_{7 \mathrm{a}}$. Alternatively, however, the path from parent brand quality to BRQ is positive and significant for all fit conditions, providing strong support for $\mathrm{H}_{5 \mathrm{~b}}$. Similarly, the path from brand portfolio breadth to BRQ is also positive and significant for all extension products, supporting $\mathrm{H}_{7 \mathrm{~b}}$. Finally, as expected, the results indicate that the path from favorable attitudinal responses to favorable behavioral responses is positive and significant for the all fit conditions, supporting $\mathrm{H}_{8}$.

\section{Discussion and implications}

As consumers develop strong relationships with brands, it is not surprising that these relationships cultivate the potential to influence consumers' attitudinal and behavioral responses toward brand-related phenomena. This study explores the role of such personal relationships consumers develop with brands in determining success likelihood of brand extensions. It is proposed that BRQ, together with fit perceptions, plays a central role in consumers' evaluations of brand extensions. The study further advances the idea that the importance of perceived fit might be overstated in current brand extension research because in attempting to explain brand extension phenomena most empirical works do not use constructs depicting special consumer-brand relationships. Interestingly, and somehow confirming the aforementioned concerns and the fundamental significance of fit perceptions, the results of the study suggest that both BRQ and perceived fit are central in terms of shaping consumer responses to brand extensions. In effect, the evidence provided in this study indicates that BRQ and perceived fit complement each other as they jointly influence consumer evaluations.

The prominent role of perceived fit in terms of determining consumer attitudes is confirmed once again by the large effect sizes observed in all fit conditions. There is evidence that, in addition to influencing attitudinal responses, perceived fit exerts direct effects on consumers' behavioral responses as well. However, these latter effects are relatively weaker and significant only in the moderate and low-fit conditions. Likewise, the study provides strong evidence confirming BRQ as a key success factor in brand extension incidents. Unlike perceived fit, however, BRQ is found to exert significant effects on behavioral responses and not on attitudinal responses, consistently for each fit condition. Thus, it appears that consumer-brand relationships could be particularly important for immediate consumer reactions to the extension product, before a clear attitude has been developed. Consumers might rely on their personal relationships with the brand in relatively ambiguous situations, when they need to display quick behavioral responses before having direct experiences with the extension product and developing a solid attitude (Fedorikhin et al. 2008). These findings indicate that BRQ might be a critical factor driving initial acceptance and trial for extension products, whereas 
fit perceptions would be more prominent for determining the overall attitude towards the extension product through time. Particularly for initial acceptance of the extension product in the marketplace, a strategic focus on BRQ is likely to yield better results than an extension strategy that stresses solely fit perceptions.

In addition, BRQ exerts strong positive effects on perceived fit, specifically in the moderate-fit condition. It seems that, when consumers encounter a moderate-fit extension, they cannot automatically categorize it as either high-fit or low-fit and thus engage in a more elaborative process. In such a situation, consumers with high levels of BRQ start thinking about the shared memories and feelings they have with the brand, and, since they have a pervasive desire to maintain the scope of their interactions, they are tempted to believe that the extension somehow fits the parent brand (Yeung, Wyer 2005). This effect is pronounced less in the high-fit condition, since the extension is quickly categorized as fitting. Thus, particularly for moderate-fit extensions, the role and importance of BRQ is indisputable since it not only shapes immediate behavioral responses but also facilitates the likelihood that the extension product would be categorized as "fitting". Marketers aiming for a successful brand extension strategy need to pay attention to emphasizing consumer-brand relationships and targeting high BRQ segments particularly in these conditions. Consumers in the target markets should be reminded of their warm memories with the brand and specific measures should be taken to identify and reach high BRQ segments to facilitate initial acceptance.

Findings regarding the effects of antecedent brand characteristics provide further evidence that BRQ and fit perceptions complement each other as they jointly mediate the effects of performance drivers on consumer responses to brand extensions. First, the results indicate clearly that, regardless of the fit condition, brand quality exerts significant effects on BRQ. In addition, because brand quality does not have significant effects on perceived fit in any of the fit conditions, it is obvious that BRQ acts as the only (partial) mediator of brand quality effects on consumer responses. Findings further indicate direct effects of brand quality on attitudinal and behavioral responses in different fit conditions. Thus, by enhancing the perceived quality in the eyes of their consumers, firms can indeed enhance the quality of consumer-brand relationships and correspondingly receive more favorable responses.

Second, brand portfolio breath exerts a strong effect on perceived fit only in the high-fit condition, whereas it has significant yet relatively weaker effects on BRQ in all fit conditions. Given that in the most fit conditions brand portfolio breadth has non-significant effects on attitudinal and behavioral responses, except for the observed negative effects on attitudinal responses in the high-fit condition and behavioral responses in the lowfit condition, it can be concluded that brand portfolio breadth is influential mostly for high-fit brand extension cases and that its impact is largely through fit perceptions and BRQ. A strategic focus stressing fit perceptions and BRQ appears to be a must for broad brands extending to high-fit categories, whereas emphasizing BRQ seems helpful for other fit conditions as well.

Findings regarding the direct effects of brand characteristics on attitudinal and behavioral responses also deserve some discussion. For instance, brand quality is found to 
influence attitudinal responses only in the high-fit condition and behavioral responses in all fit conditions (while the effect sizes are relatively weak). This discrepancy in effects across differing fit conditions may be explained based on categorization theory. In cases of high-fit, it is easier to locate an extension product quickly as a category member and transfer brand associations to the new product, thus enabling brand quality associations to shape attitudes and behaviors toward the extension. In cases of moderate or low-fit, however, since the extension product is not categorized automatically as a "member", attitudes toward the extension are not formed on the bases of brand associations. It is more likely that in the latter conditions consumers would use a risk minimization strategy and without developing attitudinal judgments of the extension product just rely on overall parent brand quality as a strong heuristic to guide behavioral responses.

In a similar vein, portfolio breadth appears to exert negative direct effects on attitudinal responses in the high-fit condition and behavioral responses in the low-fit condition. All effect sizes observed regarding the direct effects of brand portfolio breadth on attitudinal and behavioral responses other than these two are non-significant. Once again, difficulty in categorizing the extension product in the low-fit condition seems to have facilitated reliance on the brand characteristic. In addition, the observed negative direct effects of brand portfolio breadth indicate possible dual mechanisms of portfolio effects on consumer responses. That is, while broad brands by developing a strong and flexible brand image may facilitate success of extensions via fit perceptions and BRQ assessments, portfolio breadth may also have an inhibiting secondary mechanism of effects by blurring the meaning of the brand in consumers' minds. Again, marketers dealing with broad brands therefore need to put specific emphasis on facilitating fit perceptions and BRQ assessments.

\section{Conclusions}

Overall, this study contributes to the brand extension research by providing concrete evidence for the strategic importance of consumer-brand relationships. For years, the literature has advised marketers to account for fit levels in deciding whether to launch brand extensions, with the underlying assumption that marketers have little power in managing perceived fit. The results of this study, however, clearly reveal that by developing close consumer-brand relationships it might be possible to overcome the burdens of non-fitting brand extension situations. Further, it may also be possible to improve fit perceptions by emphasizing close relationships with customers.

This study confirms that perceived fit is the most important determinant of brand extension success. Nonetheless, given the fact that fit perceptions are at best difficult to manage via marketing tools, the findings revealed in the present study suggesting that by stressing consumer relations with their brands firms can actually expand the boundary of their extension products should definitely have practical value. In addition, the finding indicating that consumers rely more on BRQ rather than other factors when they need to display immediate reactions is critical for marketers attempting market new extensions and foster initial trials. These findings call for research that go beyond the transfer of 
associations from the parent brand to the extension product paradigm and highlight the importance of the concept of brand as a personal relationship partner.

Yet, findings should be assessed in the light of some limitations. First, the cross-sectional nature of the data limits confidence in causal inferences. Second, the limited nature of the stimuli used makes the generalizability of these results somewhat weak. Future works where broader product categories are examined could be highly informative. Finally, replications of the study in different cultural contexts could provide additional insights regarding the issues investigated.

Further research focusing on the specific roles of BRQ may provide a better understanding of how current and prospective customers might react to brand extensions. Specifically, the question of what happens when BRQ is low seeks further inquiry. Another important avenue for research would be the potential standing of BRQ in the context of feedback effects in both failure and success cases of extensions. Obviously, marketing researchers and practitioners would benefit substantially from integrating this brand as a personal relationship partner concept to the brand extension theory and practice.

\section{References}

Aaker, D. A.; Keller, K. L. 1990. Consumer evaluations of brand extensions, Journal of Marketing 54(1): 27-41. https://doi.org/10.2307/1252171

Albrecht, C. M.; Backhaus, C.; Gurzki, H.; Woisetschlager, D. M. 2013. Drivers of brand extension success: what really matters for luxury brands, Psychology \& Marketing 30(8): 647-659. https://doi.org/10.1002/mar.20635

Batra, R.; Ahuvia, A.; Bagozzi, R. P. 2012. Brand love, Journal of Marketing 76(2): 1-16. https://doi.org/10.1509/jm.09.0339

Boush, D. M.; Loken, B. 1991. A process tracing study of brand extension evaluations, Journal of Marketing Research 28(1): 16-28. https://doi.org/10.2307/3172723

Chun, H. H.; Park, C. W.; Eisingerich, A. B.; MacInnis, D. J. 2015. Strategic benefits of low fit brand extensions, Journal of Consumer Psychology 25: 577-595.

https://doi.org/10.1016/j.jcps.2014.12.003

Dacin, P. A.; Smith, D. C. 1994. The effects of brand portfolio characteristics on consumer evaluations of brand extensions, Journal of Marketing Research 31(2): 229- 242.

https://doi.org/10.2307/3152196

De Wulf, K.; Schröder, G. O.; Iacobucci, D. 2001. Investments in consumer relationships: a cross-country and cross-industry exploration, Journal of Marketing 65: 33-50.

https://doi.org/10.1509/jmkg.65.4.33.18386

DelVecchio, D. 2000. Moving beyond fit: the role of brand portfolio characteristics in consumer evaluations of brand reliability, Journal of Product and Brand Management 9: 457-471.

https://doi.org/10.1108/10610420010351411

Dens, N.; De Pelsmacker, P. 2010. Attitudes toward the extension and parent brand in response to extension advertising, Journal of Business Research 63: 1237-1244.

https://doi.org/10.1016/j.jbusres.2009.11.004

Dens, N.; De Pelsmacker, P. 2016. Does poor fit always lead to negative evaluations?, International Journal of Advertising 35(3): 465-485.

Dodds, W. B.; Monroe, K. B.; Grewal, D. 1991. The effects of price, brand, and store information on buyers' product evaluations, Journal of Marketing Research 28:307-319.

https://doi.org/10.2307/3172866 
Emerson, R. 1976. Social exchange theory, Annual Review of Sociology 2: 335-362. https://doi.org/10.1146/annurev.so.02.080176.002003

Fedorikhin, A.; Park, C. W.; Thomson, M. 2008. Beyond fit and attitude: the effect of emotional attachment on consumer responses to brand extensions, Journal of Consumer Psychology 18: 281-291. https://doi.org/10.1016/j.jcps.2008.09.006

Fishbein, M.; Ajzen, I. 1975. Belief, attitude, intention and behaviour. Reading, MA: AddisonWesley.

Fournier, S. 1994. A consumer-brand relationship framework for strategic brand management. Unpublished doctoral dissertation, University of Florida.

Goedertier, F.; Dawar, N.; Geuens, M.; Weijters, B. 2015. Brand typicality and distant novel extension acceptance, Journal of Business Research 68: 157-165.

https://doi.org/10.1016/j.jbusres.2014.04.005

Grime, I.; Diamantopoulos, A.; Smith, G. 2002. Consumer evaluations of extensions and their effects on the core brand, European Journal of Marketing 36: 1415-1438.

https://doi.org/10.1108/03090560210445245

Grisaffe, D. B.; Nguyen, H. P. 2011. Antecedents of emotional attachment to brands, Journal of Business Research 64: 1052-1059. https://doi.org/10.1016/j.jbusres.2010.11.002

Hem, L. E.; Iversen, N. M.; Olsen, L. E. 2014. Category characteristics' effects on brand extension attitudes, Journal of Business Research 67(8):1589-1594.

https://doi.org/10.1016/j.jbusres.2013.10.002

John, D. R.; Park, J. K. 2016. Mindset matters: implications for branding research and practice, Journal of Consumer Psychology 26(1): 153-160. https://doi.org/10.1016/j.jcps.2015.06.010

Keller, K. L.; Aaker, D. A. 1992. The effects of sequential introduction of brand extensions, Journal of Marketing Research 29: 35-50. https://doi.org/10.2307/3172491

Kim, K.; Park, J.; Kim, J. 2014. Consumer-brand relationship quality: when and how it helps brand extensions, Journal of Business Research 67(4): 591-597.

https://doi.org/10.1016/j.jbusres.2013.03.001

Klink, R. R.; Smith, D. C. 2001. Threats to external validity of brand extension research, Journal of Marketing Research 38: 326-335. https://doi.org/10.1509/jmkr.38.3.326.18864

Lane, V. R. 2000. The impact of ad repetition and ad content on consumer perceptions of incongruent extensions, Journal of Marketing 64: 80-91. https://doi.org/10.1509/jmkg.64.2.80.17996

Mervis, C. B.; Rosch, E. 1981. Categorization of natural objects, Annual Review of Psychology 32: 89-115. https://doi.org/10.1146/annurev.ps.32.020181.000513

Meyvis, T.; Janiszewski, C. 2004. When are broader brands stronger brands?, Journal of Consumer Research 31: 346-357. https://doi.org/10.1086/422113

Morgan, R. B.; Hunt, S. D. 1994. The commitment trust theory of relationship marketing, Journal of Marketing 58 (3): 20-38. https://doi.org/10.2307/1252308

Palmatier, R. W.; Dant, R. P.; Grewal, D.; Evans, K. R. 2006. Factors influencing the effectiveness of relationship marketing, Journal of Marketing 70: 136-153.

https://doi.org/10.1509/jmkg.70.4.136

Park, J. W.; Kim, K. H. 2001. Role of consumer relationships with a brand in brand extensions, Advances in Consumer Research 28: 179-185.

Park, J. W.; Kim, K. H.; Kim, J. K. 2002. Acceptance of brand extensions, Advances in Consumer Research 29: 190-198.

Sheinin, D. A.; Schmitt, B. H. 1994. Extending brands with new product concepts: the role of category attribute congruity, brand affect, and brand breadth, Journal of Business Research 31(1): 1-10. https://doi.org/10.1016/0148-2963(94)90040-X 
Song, P.; Zhang, C.; Xu, Y. C.; Huang, L. 2010. Brand extension of online technology products, Decision Support Systems 49(1): 91-99. https://doi.org/10.1016/j.dss.2010.01.005

Völckner, F.; Sattler, H. 2006. Drivers of brand extension success, Journal of Marketing 70(2): 18-34. https://doi.org/10.1509/jmkg.70.2.18

Völckner, F.; Sattler, H. 2007. Empirical generalizability of consumer evaluations of brand extensions, International Journal of Research in Marketing 24(2): 149-162.

https://doi.org/10.1016/j.ijresmar.2006.11.003

Wernerfelt, B. 1988. Umbrella branding as a signal of new product quality, The Rand Journal of Economics 19(3): 458-466. https://doi.org/10.2307/2555667

Yeung, C. W. M.; Wyer, R. S. 2005. Does loving a brand mean loving its products? The role of brand- elicited affect in brand extension evaluations, Journal of Marketing Research 42(4): 495-506. https://doi.org/10.1509/jmkr.2005.42.4.495

Esra ARIKAN, PhD, is an Assistant Professor of marketing at Istanbul Bilgi University, Turkey. She received her $\mathrm{PhD}$ in marketing from Bogazici University in 2010. Her research interests focus on consumer-brand relationships, brand extensions and services encounters.

Cengiz YILMAZ, PhD, is a Professor of marketing at Middle East Technical University, Turkey. He received his PhD in marketing from Texas Tech University in 1999. His research interests focus on distribution channels and relationship marketing, emerging technologies and their impacts on marketing applications, strategic issues concerning intra and inter-firm aspects in marketing systems and their links with business performance. His research has been published in several scholarly journals including Journal of the Academy of Marketing Science, European Journal of Marketing, Journal of Business Research, Industrial Marketing Management and Journal of World Business.

Muzaffer BODUR, PhD, is a Professor of marketing and international business at Bogazici University, Turkey. She received her PhD from Indiana University. Her publications focus on business cultures and internationalization of firms and marketing strategies of multinational firms in emerging markets. Her research has been published in several scholarly journals including European Journal of Marketing, Journal of World Business, International Journal of Advertising, Journal of International Business Studies and Journal of International Management. 